\title{
Progress Toward Eliminating Hepatitis A Disease in the United States
}

\author{
Trudy V. Murphy, MD ${ }^{1}$ \\ Maxine M. Denniston, $\mathrm{MSPH}^{1}$ \\ Holly A. Hill, MD, $\mathrm{PhD}^{2}$ \\ Marian McDonald, $\mathrm{DrPH}^{3}$ \\ Monina R. Klevens, DDS ${ }^{1}$ \\ Laurie D. Elam-Evans, $\mathrm{PhD}^{2}$ \\ Noele P. Nelson, MD, $\mathrm{PhD}^{1}$ \\ John Iskander, $\mathrm{MD}^{4}$ \\ John D. Ward, MD ${ }^{1}$ \\ ${ }^{1}$ Division of Viral Hepatitis, National Center for HIVIAIDS, Viral Hepatitis, STD, and TB Prevention, CDC \\ ${ }^{2}$ Immunization Services Division, National Center for Immunization and Respiratory Diseases, CDC \\ ${ }^{3}$ Office of Health Disparities, National Center for Zoonotic and Emerging Infectious Diseases, CDC \\ ${ }^{4}$ Office of the Associate Director for Science, Office of the Director, CDC
}

Corresponding author: Trudy Murphy, Division of Viral Hepatitis, National Center for HIV/AIDS, Viral Hepatitis, STD, and TB Prevention, CDC. Telephone: 404-639-8845; E-mail: tkm4@cdc.gov.

\section{Summary}

Hepatitis A virus (HAV) disease disproportionately affects adolescents and young adults, American Indian/Alaska Native and Hispanic raciallethnic groups, and disadvantaged populations. During 1996-2006, the Advisory Committee on Immunization Practices (ACIP) made incremental changes in hepatitis $A$ (HepA) vaccination recommendations to increase coverage for children and persons at high risk for HAV infection. This report examines the temporal association of ACIP-recommended HepA vaccination and disparities (on the absolute scale) in cases of HAV disease and on seroprevalence of HAV-related protection (measured as antibody to HAV [anti-HAV]). ACIP-recommended childhood HepA vaccination in the United States has eliminated most absolute disparities in HAV disease by age, racelethnicity, and geographic area with relatively modest $\geq 1$-dose and $\geq 2$-dose vaccine coverage. However, the increasing proportion of cases of HAV disease among adults with identified and unidentified sources of exposure underscores the importance of considering new strategies for preventing HAV infection among U.S. adults. For continued progress to be made toward elimination of HAV disease in the United States, additional strategies are needed to prevent HAV infection among an emerging population of susceptible adults. Notably, HAV infection remains endemic in much of the world, contributing to U.S. cases through international travel and the global food economy.

\section{Introduction}

Hepatitis A virus (HAV) infection can result in serious illness (HAV disease) with a risk for morbidity and mortality, particularly among susceptible older adults. Symptoms characteristically include anorexia, vomiting, malaise, fever, abdominal pain, and jaundice, similar to other types of viral hepatitis. Severe disease (e.g., fulminant hepatitis) is lifethreatening; complications are uncommon but can be longlasting (e.g., nephrotic syndrome, glomerulonephritis, vasculitis, pancreatitis, Guillain-Barré syndrome, thrombocytopenia, or aplastic anemia) (1). HAV infection is asymptomatic (without jaundice) in approximately $70 \%$ of children aged $<6$ years, whereas approximately $70 \%$ of adolescents and adults are symptomatic (2). In previous studies, adults with HAV disease averaged 27 days (range: $0-180$ days) of work loss (3). Hospitalization rates were $11 \%-22 \%$ overall, and approximately $40 \%$ among adults; case-fatality rates were
$0.3 \%$ overall, and $\geq 1.8 \%$ among persons aged $>50$ years and persons with chronic liver disease (3-5).

$\mathrm{HAV}$ is highly infectious and remains infectious for prolonged periods (i.e., months) in the environment. Transmission is fecal-oral from ingestion of HAV in contaminated food or water or contact with an infected person (3). HAV shedding in stool is heaviest before onset of symptoms, facilitating transmission. Persons who engage in certain risky behaviors (e.g., injection drug use [IDU]) and men who have sex with men (MSM) are more likely to become infected. Conditions favoring transmission include lack of access to clean water and food, poor sanitation, and crowded living conditions. Disadvantaged persons, including persons with low socioeconomic status and indigenous populations, can be affected disproportionately by these conditions (3). In the United States, spread from asymptomatically infected children has contributed to community outbreaks, particularly among children attending child care centers $(2,3,6,7)$. 
The epidemiology of acute HAV disease varies worldwide and is in transition in many areas $(8-12)$. In regions where HAV infection has been considered endemic (e.g., Africa, Asia, Central and South America, and Eastern Europe), up to $90 \%$ of children are infected by age 10 years (13). Because asymptomatic HAV infection in endemic settings is almost universal during childhood, and is associated with life-long immunity in these settings, illness and deaths from HAV infection are uncommon at any age. As sanitation, access to clean water, and living conditions improve, a decrease occurs in the proportion of persons protected by infection in childhood, HAV disease becomes more frequent among adolescents and adults, and cycles of outbreaks occur as the proportion of the population that is susceptible increases. Because improvements in conditions that foster transmission occur unevenly across communities, disparities in disease incidence can be accentuated by the quality of living conditions, geography, and race/ethnicity of affected populations $(3,9,13)$.

In the United States, transition from intermediate to low endemic HAV infection occurred during the second half of the 20th century. During this period, temporal increases in HAV infection and communitywide outbreaks led to cyclic increases in HAV disease approximately every $10-15$ years (Figure 1) $(5,11,14)$. Between cyclic increases, the number of reported cases remained $\geq 21,000$ annually (5). When underdiagnosis and underreporting are accounted for, the actual number of cases was estimated to be two to ten times higher $(5,15)$. In 1994, what appeared to be a new cycle of increasing HAV infection began, with 26,796 reported cases (rate: 10.3 cases per 100,000 population) (5).

During 1983-1997, the highest case rates were among children aged $\geq 5$ years and young adults, and the lowest case rates were among adults aged $\geq 40$ years. This pattern was still present in 2000 (Figure 2) $(3,5,6,14)$. The 19881994 National Health and Nutrition Examination Survey (NHANES) estimated that approximately one third (37.4\%; 95\% confidence interval [CI]: $35.1 \%-39.8 \%)$ of U.S. adults aged $\geq 20$ years had antibody to HAV (anti-HAV), presumably from past infection. Among the three major racial and ethnic populations evaluated by NHANES, the highest seroprevalence of anti-HAV was among Mexican-American $(81.9 \%$; 95\% CI: $79.3 \%-84.4 \%)$ and non-Hispanic black adults $(50.0 \%$; $95 \%$ CI: 47.8\%-52.2\%); the lowest prevalence was among nonHispanic white adults (29.0\%; 95\% CI: 26.9\%-31.1\%) (17).

Cases were unevenly distributed geographically across the United States. During 1987-1997, the highest case rates were in Alaska and the western states (18) (Figure 3). HAV disease also affected racial/ethnic minority populations disproportionately. Rates were well above the national average of 10.3 cases per 100,000 population among American

FIGURE 1. Incidence* of reported acute hepatitis A cases — National Notifiable Diseases Surveillance System, United States, 1966-2013

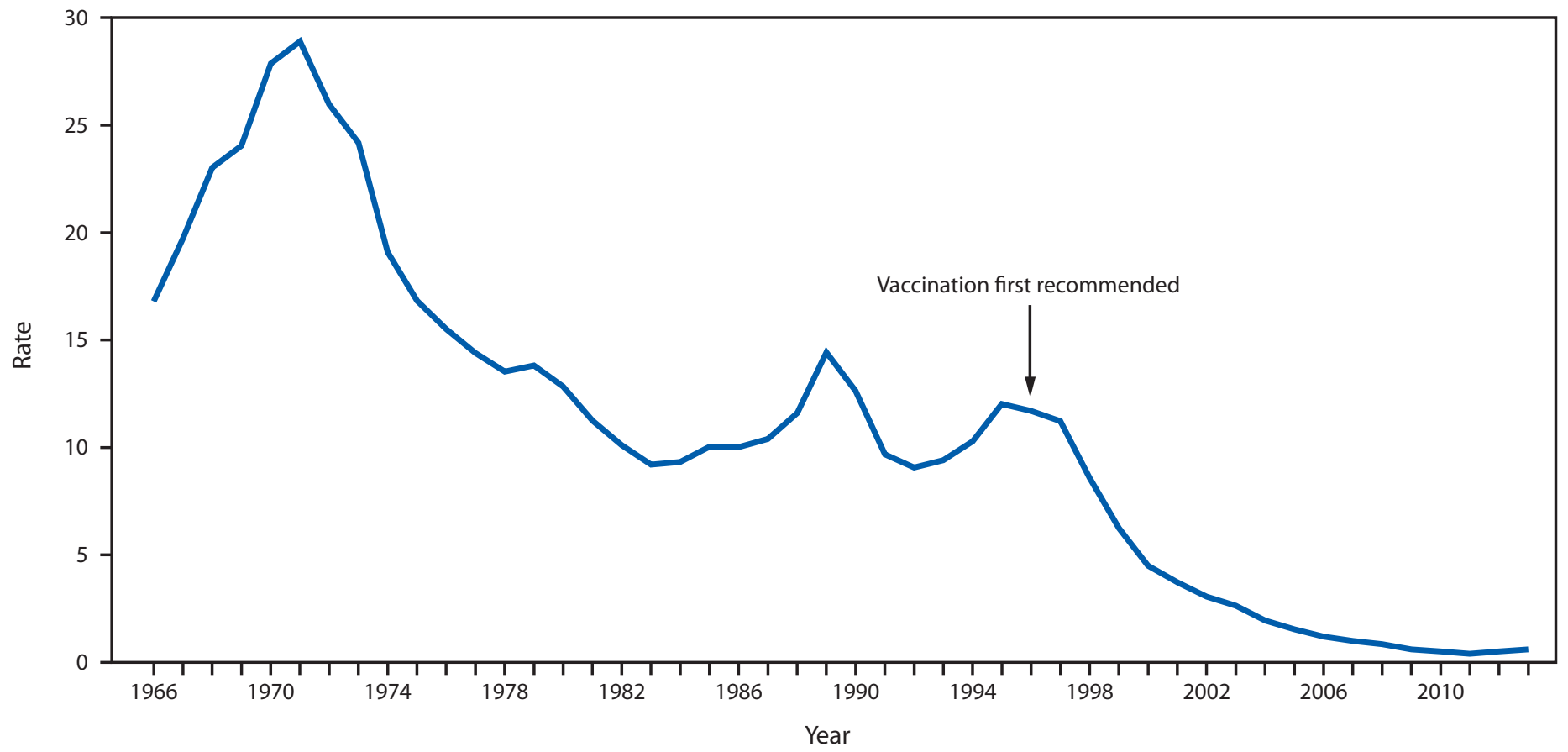

\footnotetext{
* Rate per 100,000 population. Rate (number of cases) in 1971 (peak), 1996 (first Advisory Committee on Immunization Practices [ACIP)] recommendation for hepatitis A vaccination) and 2011 (low) were 28.9 (59,606 cases), 11.7 (31,032 cases), and 0.4 (1,398 cases), respectively.
} 
Indians/Alaska Natives (AI/ANs) and Hispanics; rates were lower among non-Hispanic whites, non-Hispanic blacks, and Asians/Pacific Islanders (Figure 4) $(3,5,18)$.

To control HAV infection, CDC's Advisory Committee on Immunization Practices (ACIP) developed recommendations for hepatitis A (HepA) vaccination incrementally in 1996, 1999, and 2006. Initially, persons living in areas experiencing community outbreaks and high rates of infection were targeted for vaccination, and eventually universal childhood HepA vaccination was recommended $(3,6,18)$. This report describes the HepA vaccination program in the United States, its impact on elimination of disparities (on the absolute scale) in the incidence of HAV disease, and new challenges posed by disparities in HAV seroprotection.

CDC's Office of Minority Health and Health Equity selected the intervention analysis and discussion that follows to provide an example of a program that has been effective in reducing hepatitis A-related disparities in the United States. Criteria for selecting this program are described in the Background and Rationale for this supplement (19).

\section{Methods}

\section{Interventions}

Inactivated HepA vaccines were approved in the United States in 1995 and 1996 for use in 2-dose schedules at age $\geq 2$ years (20). A trial in New York among 1,037 children aged 2-16 years found $100 \%$ (95\% CI: $87.3 \%-100.0 \%$ ) efficacy 6-18 months after a single dose of Vaqta (Merck and Company, West Point, Pennsylvania) (21). Another trial in Thailand among 38,157 children aged 1-16 years found 94\% (95\% CI: 79\%-99\%) efficacy after 2 doses of Havrix (GlaxoSmithKline Biologics, King of Prussia, Pennsylvania) administered 1 month apart (22). Anti-HAV levels associated with protection and reduction in viral shedding were achieved in $97 \%-100 \%$ of children and adolescents by 1 month after a single dose; $100 \%$ of children had protective levels of antibody after a second dose (G). In 2005, the Food and Drug Administration (FDA) approved both inactivated HepA vaccines for use at age $\geq 12$ months (20).

Since the introduction of the HepA vaccine, ACIP has recommended HepA vaccination as a control measure in

FIGURE 2. Incidence* of reported acute hepatitis A cases, by age group - National Notifiable Diseases Surveillance System, United States, 2000-2013

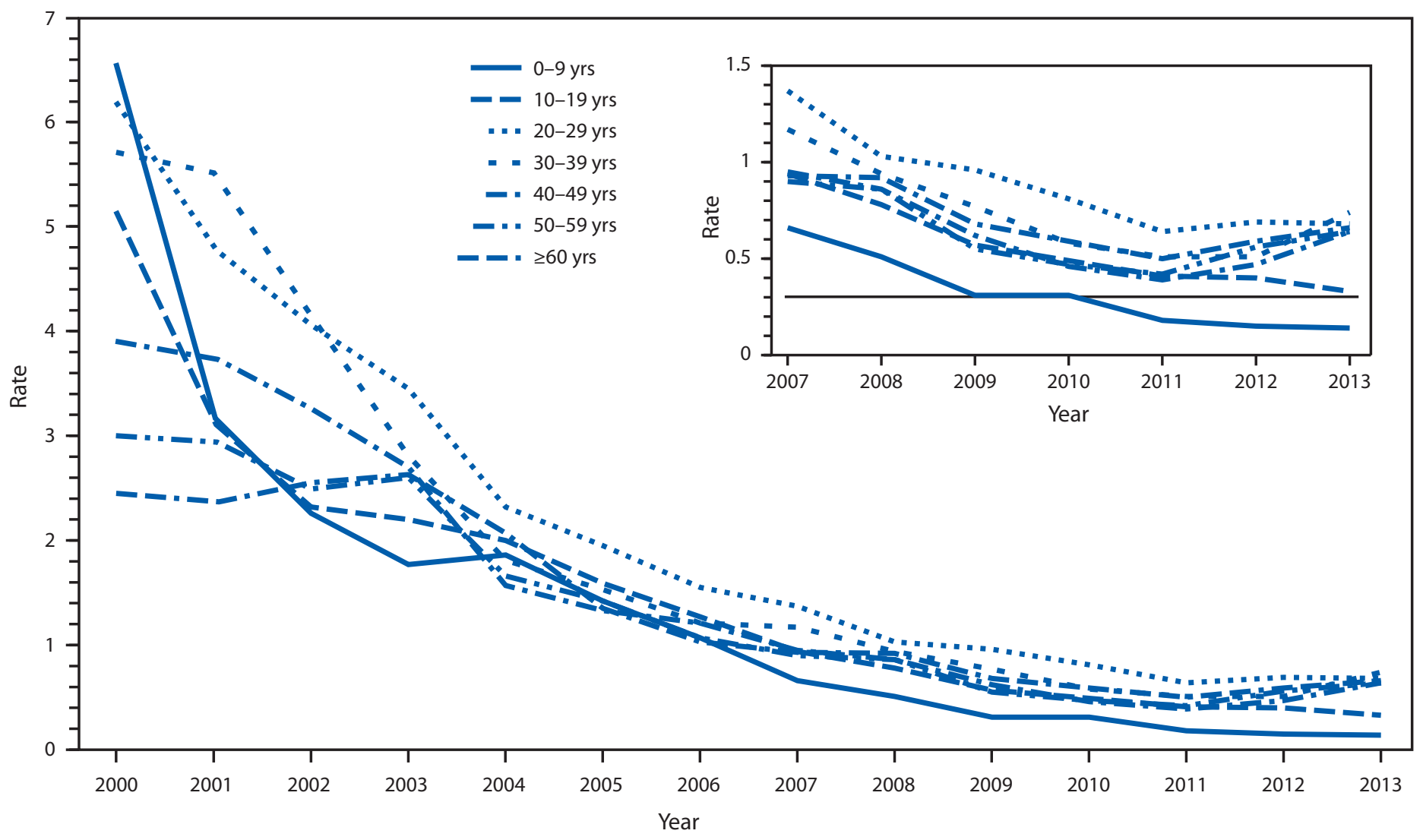

* Rate per 100,000 population. 
FIGURE 3. Incidence* of reported acute hepatitis A cases, by county - National Notifiable Diseases Surveillance System, United States, $1987-1997^{\dagger}$ (pre-vaccine) and 2007

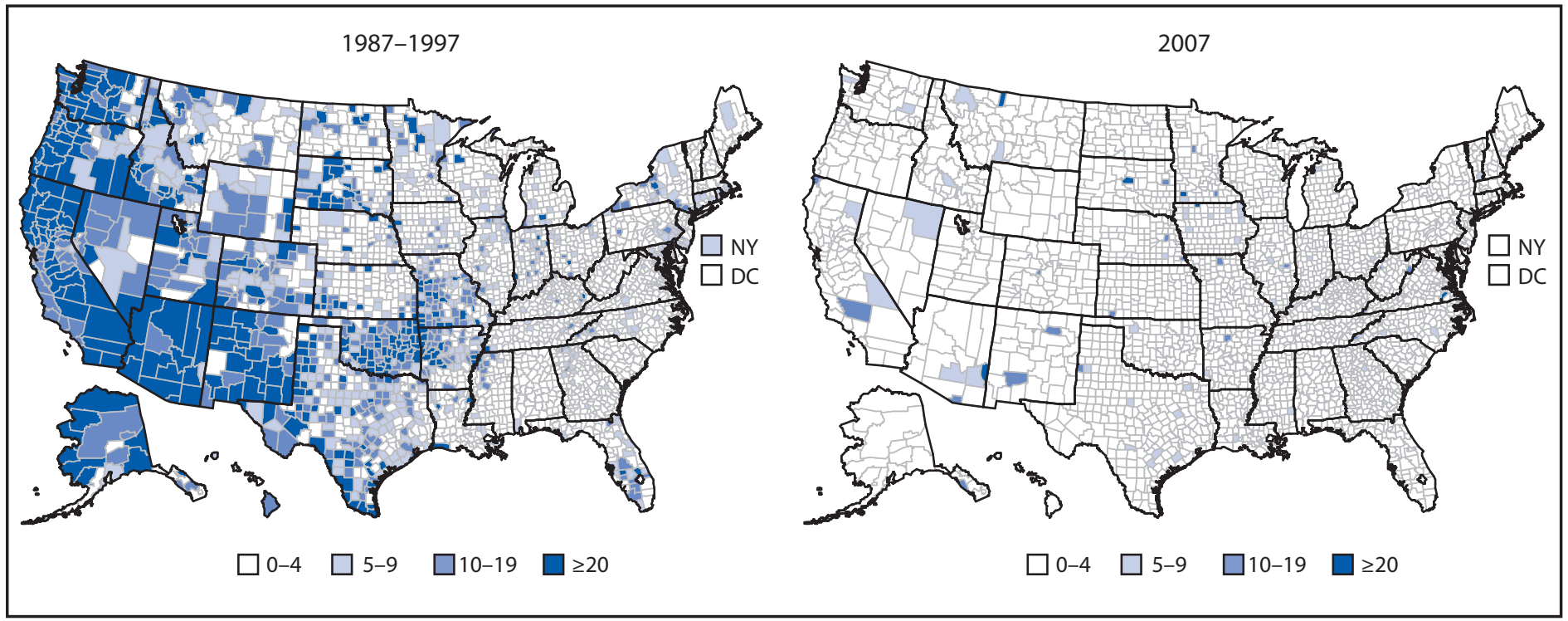

* Rate per 100,000 population.

† Annual average incidence.

FIGURE 4. Incidence* of reported acute hepatitis A cases, by race/ethnicity — National Notifiable Diseases Surveillance System, United States, 1990-2013

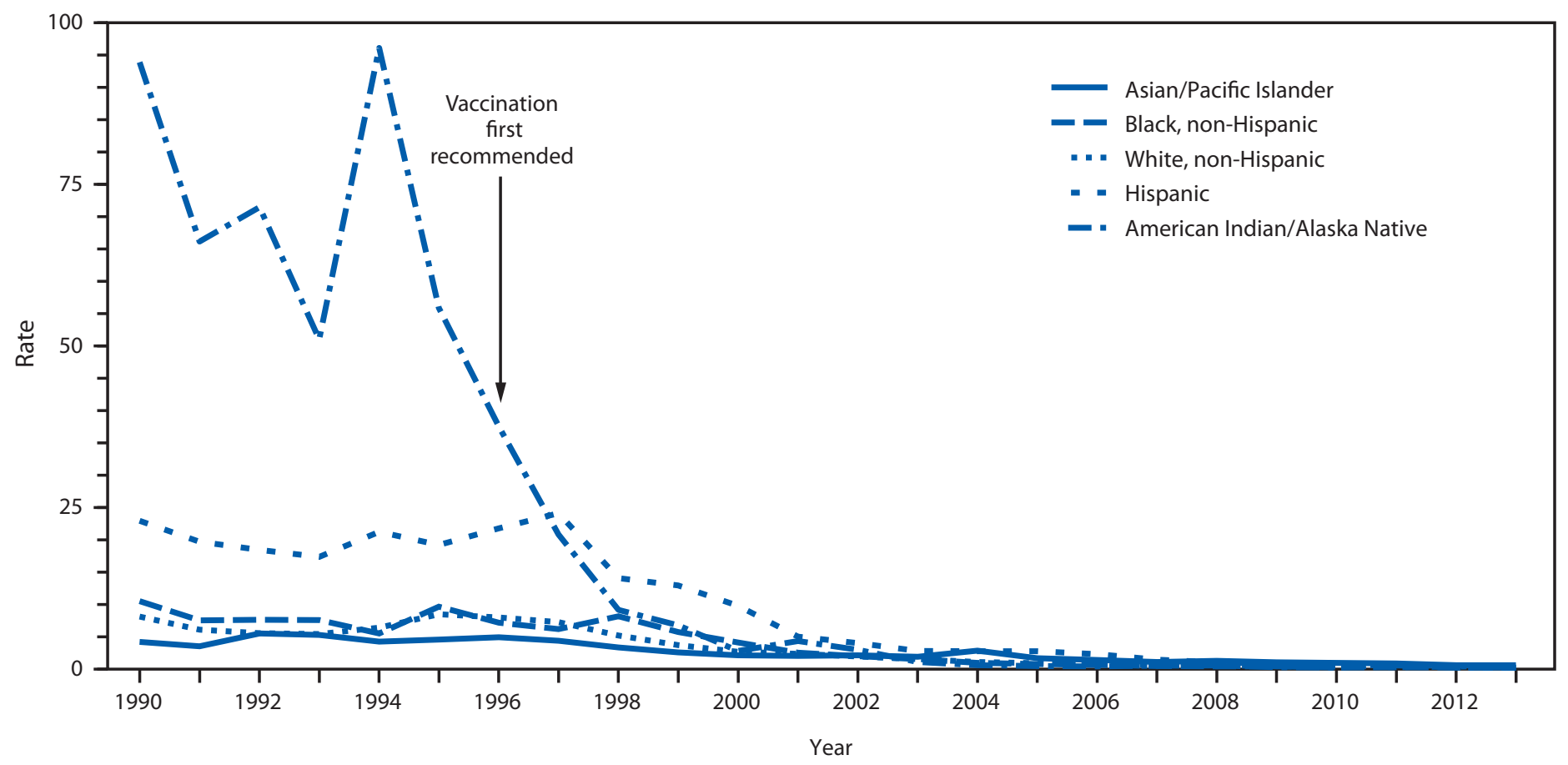

* Rate per 100,000 population.

outbreaks, for populations at increased risk, for persons who have chronic liver disease, as routine vaccination for children aged 12-23 months and for anyone wishing to obtain immunity (Box) $(3,6,18)$. During 1996-2006, ACIP made incremental changes in HepA vaccination recommendations to increase coverage for children and persons at highest risk for HAV infection. 
Supplement

BOX. Childhood hepatitis A vaccination recommendations - Advisory Committee on Immunization Practices, 1996-2006

\section{6}

1. Routine hepatitis A (HepA) vaccination for children aged $\geq 2$ years and accelerated vaccination of older children (including children to age 10-15 years) to control ongoing outbreaks in communities that have high rates of hepatitis A and periodic hepatitis A outbreaks.

2. Vaccinate populations at increased risk for hepatitis A infection (e.g., persons traveling to or working in countries that have high or intermediate endemnicity of infection, men who have sex with men, illegal-drug users, persons who have occupational risk for infection, and persons who have clotting-factor disorders) or persons who have chronic liver disease.

3. Vaccinate any person wishing to obtain immunity.

\section{9}

1. Routine HepA vaccination for children aged $\geq 2$ years who live in states, counties, or communities where the average annual rate during 1987-1997 was $\geq 20$ cases per 100,000 population (i.e., approximately twice the national average of 10.8 cases per 100,000 population) (included 11 states: Alaska, Arizona, California, Idaho, Nevada, New Mexico, Oklahoma, Oregon, South Dakota, Utah, and Washington).

2. Consider routine HepA vaccination for children aged $\geq 2$ years living in states, counties, or communities where the average annual rate of hepatitis A during 1987-1997 was $\geq 10$ cases per 100,000 population but $<20$ cases per 100,000 population (six states: Arkansas, Colorado, Missouri, Montana, Texas, and Wyoming).

3. Vaccinate older children (e.g., up to age 10-15 years) in communities with high rates of hepatitis A to prevent epidemics.

4. Vaccinate persons at increased risk for hepatitis A and persons who have chronic liver disease (see 1996, above).

5. Vaccinate any person wishing to obtain immunity.

\section{6}

1. Routine HepA vaccination for all children in the United States at age 12-23 months.

2. Continue HepA vaccination for children ages 2-18 months in states, counties and communities with existing vaccination programs.

3. Consider catch-up vaccination for children ages 2-18 years in areas without existing programs, especially when incidence is increasing or with ongoing outbreaks among children and adolescents.

4. Vaccinate persons at increased risk for HAV and persons who have chronic liver disease (see 1996 above).

5. Vaccinate any person wishing to obtain immunity.

Sources: Adapted from CDC. Prevention of hepatitis A through active or passive immunization: recommendations of the Advisory Committee on Immunization Practices (ACIP). MMWR Recomm Rep 1996;45(No.RR-15); CDC. Prevention of hepatitis A through active or passive immunization: recommendations of the Advisory Committee on Immunization Practices (ACIP). MMWR Recomm Rep 1999;48(No.RR-12); CDC. Prevention of hepatitis through active or passive immunization: recommendations of the Advisory Committee on Immunization Practices (ACIP). MMWR Recomm Rep 2006;55(No.RR-7).

Risk for infection for unvaccinated persons is related to the prevalence of HAV in the community $(9,11,12)$. The 1996 ACIP recommendations were directed at controlling outbreaks and preventing HAV infection in high-risk persons (3). In 1999, ACIP stratified its recommendations (i.e., "recommend" vaccination or "consider" vaccination) on the basis of the incidence of HAV disease in geographic locations (G). ACIP recommended routine HepA vaccination for children aged $\geq 2$ years who were living in states, counties, and communities with rates of HAV disease at least twice the national average. During 1987-1997, the national average HAV rate was 10.8 cases per 100,000 population. In 1999, a total of 11 states (Alaska, Arizona, California, Idaho, Nevada, New Mexico, Oklahoma, Oregon, South Dakota, Utah, and Washington) had an average annual rate of $\geq 20$ cases per 100,000 population (i.e., twice the national average). ACIP recommended that $\mathrm{HepA}$ vaccination be considered for children aged $\geq 2$ years who were living in states, counties, and communities with rates of HAV disease $\geq 10$ cases per 100,000 population but $<20$ cases per 100,000 population. In 1999, six states met these criteria: Arkansas, Colorado, Missouri, Montana, Texas, and Wyoming. The remaining 33 states (i.e., nonvaccinating states) and the District of Columbia (DC) did not meet the ACIP incidence thresholds for HepA vaccination. ACIP recommended that older children (e.g., up to age 10-15 years) residing in communities with high rates of HAV disease be vaccinated to prevent epidemics. States that met incidence criteria for "recommend" vaccination (11 states) or "consider" vaccination (six states) were encouraged to consider 
strategies for increasing childhood HepA vaccination rates (e.g., vaccination before entering child care or school or when making health care visits for other purposes) (G).

In 2006, ACIP recommended HepA vaccination at age 12-23 months for all children in the United States (18). ACIP encouraged continuation of existing HepA vaccination programs for children aged 2-18 years and consideration of catch-up vaccination, especially in the context of increasing incidence or ongoing outbreaks among children or adolescents (18).

\section{Data Collection and Analysis}

This report summarizes results from published literature and novel CDC analyses. These results are derived from multiple data sources including the National Immunization Survey (NIS), NIS-Teen, the National Health Interview Survey (NHIS), and the National Notifiable Disease Surveillance System (NNDSS). Certain results for HepA vaccination coverage are presented by the state's status (i.e., incidence of HAV disease and the 1999 ACIP stratified HepA vaccination recommendations): recommended (11 states), considered (six states), or nonvaccinating (33 states and DC).

NIS provides vaccine coverage estimates at the national, state, and selected local area levels (23). NIS began collecting data on HepA vaccine coverage among children aged 24-35 months in 2003 (24). After ACIP recommended routine HepA vaccination for children aged 12-23 months in 2006, data for children aged 19-35 months were collected and reported as national $\geq 2$-dose coverage for 2008 and 2010, and as national $\geq 1$ dose coverage for 2009 (25-27). Starting in 2011, national HepA coverage was reported annually as $\geq 1$ and $\geq 2$ doses, and national coverage for $\geq 1$ dose and $\geq 2$ doses was included in the reports for up to four years retrospectively (28-30). NIS reports for 2008, 2010-2013 also included $\geq 2$-dose HepA coverage by economic status (at or above the poverty level or below the poverty level), and by mutually exclusive race/ethnicity categories (non-Hispanic white only, non-Hispanic black only, Hispanic [in combination with any race], non-Hispanic Asian only, and non-Hispanic multiracial). In 2009, NIS data for HepA vaccine coverage were reported for $\geq 1$ dose by mutually exclusive race/ethnicity categories including non-Hispanic AI/AN, and non-Hispanic Native Hawaiian or Other Pacific Islander (NHOPI) (27).

To summarize progress toward eliminating HAV disease in the United States, CDC analyzed or reanalyzed NIS HepA coverage data for children 19-35 months by year (2008-2013) and number of doses $(\geq 1$ and $\geq 2)$. This report includes national coverage estimates, and coverage estimates according to 1999 ACIP "recommended" (11 states), "considered" (six states), or nonvaccinating (33 states and DC) status, by economic status, and by mutually exclusive race/ethnicity categories. Data for non-Hispanic AI/AN only and NHOPI only categories also were included.

Subjects interviewed for NIS were identified via randomdigit dialing, which included both landlines and, starting in 2011, cellular telephone numbers. Demographic information and health insurance status were collected by telephone interview of a parent or guardian from households with an age-eligible child. After consent, a mail survey of vaccination providers was used to obtain the child's vaccination history. The data were weighted to be representative of the population of U.S. children aged 19-35 months. Adjustments were made to compensate for nonresponse and for households without telephones and those with multiple phone lines or mixed telephone use (i.e., landlines and cellular).

For older children and adults, HepA vaccination coverage rates were taken from published surveys. Estimates for adolescents aged 13-17 years were from the NIS-Teen and estimates for adults aged $18-49$ years were from the NHIS $(31,32)$.

The number and rates of HAV disease cases overall, by race/ethnicity, age, and state were obtained from published surveillance data from NNDSS. NNDSS receives weekly reports from state health departments summarizing results of case investigations conducted by local and state health department personnel $(5,15,33,34)$.

CDC estimated the prevalence of anti-HAV from NHANES data. NHANES conducts surveys in 2-year cycles of a representative sample of the noninstitutionalized U.S. civilian population. Survey data from 1999-2000 and 2009-2010 were used to estimate anti-HAV prevalence among U.S.born persons aged $\geq 6$ years. The prevalence of anti-HAV was compared between the two survey cycles by age, and prevalence was compared in 2009-2010 for U.S.-born non-Hispanic whites, non-Hispanic blacks, and Hispanics. Sample sizes were insufficient to examine other racial and ethnic groups among U.S.-born persons (35). Analysis was performed in SAS-callable SUDAAN (Version 11.0) using sampling weights to produce population estimates. A p value of $<0.05$ was considered significant.

Measurement of total anti-HAV was performed at CDC using the HAVAB-EIA solid phase EIA Assay (Abbott Diagnostics, Chicago, Illinois) for 1999-2000 and the Vitros HAV-T Anti-HAV Total assay (VITROS Immunodiagnostic System, Ortho-Clinical Diagnostics, Inc., Rochester, New York) for 2009-2010.* A positive result was defined for

\footnotetext{
* This qualitative assay was assessed for cut-off in $\mathrm{mIU} / \mathrm{mL}$ using a World Health Organization Second International Standard dilutional series against three master lots of the anti-HAV total reagents. The concentration at the cut-off assay mean was $30 \mathrm{mIU} / \mathrm{mL}$ (range: $29-31 \mathrm{mIU} / \mathrm{mL}$ ) (Maria-Magdalena Patru, Ortho Clinical Diagnostics, personal communication, 2014).
} 
purposes of this analysis as having anti-HAV likely to correlate with protection. The serologic correlate of protection against HAV disease is not well defined but has been estimated as antiHAV of approximately $20 \mathrm{IU} / \mathrm{mL}$ (11). Assays for anti-HAV do not distinguish between antibody induced by HAV infection and antibody induced by HepA vaccination.

\section{Results}

\section{Hepatitis A Vaccination Coverage}

In CDCs analyses, significant differences were found for 2008-2013 estimates of $\geq 1$-dose HepA vaccine coverage among children aged 19-35 months by states according to 1999 ACIP recommended, considered, or nonvaccinating status. Coverage was highest in the 11 states where HepA vaccination was recommended, slightly slower in the six states where HepA vaccination was to be considered, and lowest in states where HepA vaccination was not recommended until 2006. By $2013, \geq 1$-dose HepA vaccine coverage was $82 \%-86 \%$ in the three groups of states, and remaining disparities were decreasing. The pattern of $\geq 2$-dose HepA vaccine coverage, although at a lower level, was similar to $\geq 1$-dose HepA vaccine coverage reaching $53 \%-57 \%$ in 2013 . Differences among 1999 vaccinating (recommended and considered) and nonvaccinating states were no longer significant in 2010, 2012, and 2013 (Table 1).

CDC analyses showed children living below the poverty level had greater HepA $\geq 1$-dose vaccine coverage than children at or above the poverty level during 2008-2010. During 20082013, HepA $\geq 2$-dose coverage was similar for children above or at the poverty level and below the poverty level, except in 2012, when children above and at the poverty level had greater coverage than children below the poverty level (Table 2).

Differences in HepA coverage were substantial among racial/ ethnic groups for both $\geq 1$ dose and $\geq 2$ doses. Hispanic and Asian children had the greatest point estimates for $\geq 1$-dose and $\geq 2$-dose coverage in 2008. Point estimates of HepA vaccine coverage remained consistently lower among non-Hispanic white and non-Hispanic black children than among children in other racial/ethnic groups. Nevertheless, in 2013, $\geq 1$-dose coverage had increased to $80 \%$ and $82 \%$ among non-Hispanic white and non-Hispanic black children, respectively (Table 3).

Published 2009 NIS-Teen data for national $\geq 1$-dose and $\geq 2$-dose HepA coverage among adolescents aged $13-17$ years were $42.0 \%$ (95\% CI: $40.8 \%-43.2 \%)$ and $29.5 \%(95 \%$ CI: $28.3 \%-30.7 \%$ ), respectively (31). Differences were evident among states stratified by 1999 ACIP recommended, considered, or nonvaccinating status. Coverage with $\geq 1$ dose and $\geq 2$ doses was $74.3 \%$ (95\% CI: $71.1 \%-77.1 \%$ ) and 60.4\% (95\% CI: $56.8 \%-63.9 \%)$ in areas recommended for vaccination, $54.0 \%$ (95\% CI: $50.5 \%-57.4 \%)$ and $38.7 \%$ (95\% CI: $35.5 \%-42.2 \%$ ) in areas considered for vaccination, and $27.8 \%$ (95\% CI: 26.6\%-29.0\%), and $16.3 \%$ (95\% CI: $15.4 \%-17.3 \%)$ in nonvaccinating states, respectively (31). Coverage by race/ethnicity showed a pattern similar to that seen among children aged 19-35 months in the CDC analysis for this report (Table 3).

Published NHIS estimates of national $\geq 2$-dose HepA vaccine coverage are from self-report of vaccination. Estimates for 2007 among adults aged 18-49 years and 2012 among adults aged 19-49 years were similar, $12.1 \%$ (95\% CI: 9.9\%-14.8\%) and $12.2 \%$ (95\% CI: $11.5 \%-13.0 \%)$, respectively $(36,37)$. In 2012, coverage was higher among adults who had traveled outside the United States since 1995 to a country of high or intermediate hepatitis A endemicity (18.9\%; 95\% CI: $17.6 \%-20.3 \%$ ) (37). In contrast to estimates from NIS for children aged 19-35 months, and NIS-Teen for adolescents aged 13-17 years, NHIS HepA coverage among Hispanic adults was lower in 2007 and 2012 (7.1\%; 95\% CI: $4.3 \%-11.6 \%$ and $10.5 \%$; $95 \%$ CI: $9.2 \%-11.9 \%$, respectively) than among other racial/ethnic groups, and significantly lower than among non-Hispanic whites, whose coverage rates were similar to national coverage rates $(36,37)$.

\section{Acute Hepatitis A in the Vaccine Era}

Reports from NNDSS documented a steady decline in the annual rate of HAV disease from 11.7 cases per 100,000 population in 1996 to 2.6 cases per 100,000 population in 2003 (5). Rates of HAV disease in 17 states with HepA vaccination previously recommended (11 states) or considered (six states) were lower than rates in the 33 previously nonvaccinating states and DC (2.5 and 5.7 cases per 100,000 population, respectively) (16). Disparities in the distribution of cases by geographic area decreased notably nationwide, and by 2007 had almost disappeared (5) (Figure 3). Rates of HAV disease declined 96.6\% from 1996 to 2011 (from 11.7 to 0.4 cases per 100,000 population), and the number of reported cases decreased from 31,032 to 1,398, respectively (Figure 1). Previously observed cyclic increases in HAV disease disappeared. Starting in 2007, children aged $\geq 9$ years had the lowest rate of HAV disease of any age group; the rate of HAV disease was $<1$ case per 100,000 population in all age groups starting in 2009 (Figure 2) (15).

Declines in rates of HAV disease were most striking by racial/ethnic group. From the average rate for 1990-1997 to 2003, the rate of HAV disease among Native Americans 
TABLE 1. Estimated national $\geq 1$-dose and $\geq 2$-dose coverage of hepatitis $A$ vaccine among children aged 19-35 months by reporting year and by 1999 ACIP hepatitis A vaccine recommendations* — National Immunization Survey, United States, 2008-2013

\begin{tabular}{|c|c|c|c|c|c|}
\hline & & & 11 states $^{\dagger}$ & 6 states $^{\S}$ & 33 states and DCף \\
\hline No. of doses & Year & $\begin{array}{c}\text { National } \\
\%(95 \% \mathrm{Cl})\end{array}$ & $\begin{array}{c}\text { HepA vaccination } \\
\text { recommended for } \\
\text { children aged } \geq 2 \text { years } \\
\%(95 \% \mathrm{Cl})\end{array}$ & $\begin{array}{c}\text { HepA vaccination } \\
\text { considered for } \\
\text { children aged } \geq 2 \text { years } \\
\%(95 \% \mathrm{Cl})\end{array}$ & $\begin{array}{c}\text { No routine HepA } \\
\text { vaccination for } \\
\text { children aged } \geq 2 \text { years } \\
\%(95 \% \mathrm{Cl})\end{array}$ \\
\hline \multirow[t]{6}{*}{$\geq 1$} & 2013 & 83.1 (81.9-84.3) & 86.1 (82.5-89.7) & $84.4(81.8-87.0)$ & $81.6(80.2-83.0)^{* *}$ \\
\hline & 2012 & $81.5(80.4-82.6)$ & 85.5 (82.4-88.6) & $83.3(81.0-85.6)$ & $79.3(78.0-80.6)^{\dagger \dagger}$ \\
\hline & 2011 & $81.2(80.2-82.2)$ & 86.7 (84.5-88.9) & 83.5 (81.1-85.9) & $78.2(76.9-79.5)^{\dagger \dagger}$ \\
\hline & 2010 & 78.3 (77.2-79.4) & 82.5 (79.4-85.6) & $82.0(80.0-84.0)$ & $75.6(74.3-76.9)^{\dagger \dagger}$ \\
\hline & 2009 & $75.0(73.9-76.1)$ & 83.4 (80.9-85.9) & $78.1(75.4-80.8)$ & $70.8(69.4-72.2)^{\dagger \dagger}$ \\
\hline & 2008 & 70.5 (69.4-71.6) & $83.0(80.8-85.2)$ & $77.0(73.9-80.1)$ & $63.8(62.4-65.2)^{\dagger \dagger}$ \\
\hline \multirow[t]{6}{*}{$\geq 2$} & 2013 & $54.7(53.1-56.3)$ & $56.8(52.1-61.5)$ & $57.4(53.6-61.2)$ & $53.1(51.4-54.8)$ \\
\hline & 2012 & $53.0(51.5-54.5)$ & $54.3(49.9-58.7)$ & $55.5(52.5-58.5)$ & $51.9(50.4-53.4)$ \\
\hline & 2011 & $52.2(50.8-53.6)$ & $56.5(52.8-60.2)$ & $54.7(51.4-58.0)$ & $49.7(48.2-51.2)^{\dagger \dagger}$ \\
\hline & 2010 & $49.7(48.3-51.1)$ & $51.9(48.1-55.7)$ & $50.1(46.9-53.3)$ & $48.8(47.3-50.3)$ \\
\hline & 2009 & $46.6(45.2-48.0)$ & $51.0(47.4-54.6)$ & $47.6(43.7-51.5)$ & $44.6(43.1-46.1)^{\dagger \dagger}$ \\
\hline & 2008 & 40.4 (39.2-41.6) & $45.6(42.5-48.7)$ & $44.2(40.3-48.1)$ & $37.2(35.8-38.6)^{\dagger \dagger}$ \\
\hline
\end{tabular}

Sources: Include estimates of national coverage for 2008-2013. CDC. National, state and local area vaccination coverage among children aged 19-35 months-United States, 2008. MMWR Morb Mortal Wkly Rep 2009;58:921-6; Byrd KK, Santibanez TA, Chaves SS. Predictors of hepatitis A vaccination among young children in the United States. Vaccine 2011;29:3254-9; CDC. National, state, and local area vaccination coverage among children aged 19-35 months-United States, 2010. MMWR Morb Mortal Wkly Rep 2011;60:1157-63; CDC. National, state, and local area vaccination coverage among children aged 19-35 months-United States, 2011. MMWR Morb Mortal Wkly Rep 2012;61:689-96; CDC. National, state, and local area vaccination coverage among children aged 19-35 months-United States, 2012. MMWR Morb Mortal Wkly Rep 2013;62:733-40; CDC. National, state, and local area vaccination coverage among children aged 19-35 months-United States, 2013. MMWR Morb Mortal Wkly Rep 2014;63:741-8.

Abbreviations: $\mathrm{ACIP}=$ Advisory Committee on Immunization Practices; $\mathrm{Cl}=$ confidence interval; $\mathrm{DC}=$ District of Columbia; HepA = hepatitis $\mathrm{A}$ vaccine.

* In 1999, ACIP recommendations for children aged $\geq 2$ years were stratified (i.e., "recommend" vaccination, "consider" vaccination or no recommendation for routine vaccination) on the basis of the incidence of HAV disease in geographic locations.

† Eleven states with 1987-1997 average rate of $\geq 20$ cases of acute HAV infection per 100,000 population and recommended HepA vaccination for children aged $\geq 2$ years in 1999: Alaska, Arizona, California, Idaho, Nevada, New Mexico, Oklahoma, Oregon, South Dakota, Utah, and Washington.

$\S$ Six states with 1987-1997 average rate of $\geq 10$ cases of acute HAV infection per 100,000 population and considered HepA vaccination for children aged $\geq 2$ years in 1999: Arkansas, Colorado, Missouri, Montana, Texas, and Wyoming.

I Thirty-three states and the District of Columbia with 1987-1997 average rate $<10$ cases of acute HAV per 100,000 population and no recommendation for routine HepA vaccination for children in 1999: Alabama, Connecticut, Delaware, Florida, Georgia, Hawaii, Illinois, Indiana, lowa, Kansas, Kentucky, Louisiana, Maine, Maryland, Massachusetts, Michigan, Minnesota, Mississippi, Nebraska, New Hampshire, New Jersey, New York, North Carolina, North Dakota, Ohio, Pennsylvania, Rhode Island, South Carolina, Tennessee, Vermont, Virginia, West Virginia, Wisconsin and the District of Columbia.

** Statistically significant differences $(p<0.05)$ in estimated coverage by ACIP recommendation: 11 states, 6 states, and 33 states and DC.

t+ Statistically significant differences $(p<0.01)$ in estimated coverage by ACIP recommendation: 11 states, 6 states, and 33 states and DC.

and Hispanics decreased by $98.8 \%$ (95\% CI: 98.4\%-99.2\%) and $86.4 \%$ (95\% CI: $85.3 \%-87.1 \%)$ to 0.8 and 2.8 cases per 100,000 population, respectively $(16,38)$. Rates of HAV disease among non-Hispanic whites, non-Hispanic blacks, and Asians/Pacific Islanders decreased by $78.3 \%$ (95\% CI: 77.1\%-78.9\%), 80.5\% (95\% CI: 79.0\%-82.6\%), and $63.0 \%$ (95\% CI: $57.1 \%-68.9 \%$ ), to $1.5,1.5$, and 1.7 cases per 100,000 population, respectively (16). By 2011, national rates of HAV disease among all racial/ethnic groups had declined to $<1.0$ case per 100,000 population, virtually eliminating absolute disparities among racial/ethnic groups (Figure 4) (15).

Despite these historic declines, in 2011, approximately 1,400 cases of HAV disease were reported, and in 2012, reports of 1,562 cases represented the first increase in cases since 1995, when HepA vaccine became available in the United States $(\mathrm{p}<0.01)$ (5,39). Among cases in 2012, rates continued to decline for children aged $\leq 19$ years but increased for adults aged
$40-49$ years $(\mathrm{p}=0.07)$, for adults aged $\geq 50$ years $(\mathrm{p}<0.05)$, and among non-Hispanic whites $(\mathrm{p}<0.01)$. An estimated $45.8 \%$ of persons with HAV cases were hospitalized, and $0.6 \%$ died, which represented increases from previous years. Interviews to determine possible sources of exposure were available for $63.5 \%$ of cases; a source was identified in only $20.3 \%$ of cases, representing $13 \%$ of all cases. The majority of possible exposures were attributed to international travel outside the United States and Canada (12.9\%) and to contact with an HAV-infected person (approximately 8.1\%). Outbreaks associated with contaminated food or water accounted for $1.8 \%$ of cases (39). In 2013, reported cases increased again to 1,781 (34). Contributing to the increase in 2013 was a foodborne outbreak tied to contaminated pomegranate arils imported from Turkey, which sickened 165 patients in 10 states. Most (93\%) persons with cases in the 2013 outbreak were aged $\geq 18$ years; $42 \%$ were hospitalized, three developed fulminant hepatitis, and one required a liver transplant (40). 
TABLE 2. Estimated national $\geq 1$-dose and $\geq 2$-dose coverage of hepatitis A vaccine among children aged 19-35 months, by reporting year, and income above and at or below the poverty level ${ }^{*}$ National Immunization Survey, United States, 2008-2013

\begin{tabular}{lccc}
\hline $\begin{array}{c}\text { No. of } \\
\text { doses }\end{array}$ & Year & $\begin{array}{c}\text { Above and at poverty } \\
\text { level } \\
\%(95 \% \mathrm{Cl})\end{array}$ & $\begin{array}{c}\text { Below poverty level } \\
\%(95 \% \mathrm{Cl})\end{array}$ \\
\hline$\geq 1$ & 2013 & $82.7(81.2-84.2)$ & $84.0(81.7-86.3)$ \\
& 2012 & $82.3(81.0-83.6)$ & $80.8(78.7-82.9)$ \\
& 2011 & $80.3(79.1-81.5)$ & $82.4(80.6-84.2)$ \\
& 2010 & $77.0(75.6-78.4)$ & $80.7(78.7-82.7)^{\dagger}$ \\
& 2009 & $73.2(71.9-74.5)$ & $78.3(76.1-80.5)^{\dagger}$ \\
$\geq 2$ & 2008 & $68.9(67.6-70.2)$ & $73.6(71.2-76.0)^{\dagger}$ \\
& 2013 & $56.1(54.2-58.0)$ & $53.5(50.6-56.4)$ \\
& 2012 & $55.4(53.6-57.2)$ & $49.4(46.7-52.1)^{\dagger}$ \\
& 2011 & $53.4(51.8-55.0)$ & $50.7(48.2-53.2)$ \\
& 2010 & $49.1(47.5-50.7)$ & $51.0(48.3-53.7)$ \\
& 2009 & $46.2(44.7-47.7)$ & $47.3(44.3-50.3)$ \\
& 2008 & $40.8(39.4-42.2)$ & $39.7(37.1-42.3)$ \\
\hline
\end{tabular}

Sources: Include 2008 and 2010-2013 data for $\geq 2$ dose estimates and 2009 data for $\geq 1$ dose estimate of below the poverty level. CDC. National, state, and local area vaccination coverage among children aged 19-35 months-United States, 2008. MMWR Morb Mortal Wkly Rep 2009;58:921-6; CDC. National, state, and local area vaccination coverage among children aged 19-35 monthsUnited States, 2010. MMWR Morb Mortal Wkly Rep 2011;60:1157-63; CDC. National, state, and local area vaccination coverage among children aged 19-35 months-United States, 2011. MMWR Morb Mortal Wkly Rep 2012;61:689-96; CDC. National, state, and local area vaccination coverage among children aged 19-35 months-United States, 2012. MMWR Morb Mort I Wkly Rep 2013;62:73340; CDC. National, state, and local area vaccination coverage among children aged 19-35 months-United States, 2013. MMWR Morb Mortal Wkly Rep 2014;63:741-8; Byrd KK, Santibanez TA, Chaves SS. Predictors of hepatitis A vaccination among young children in the United States. Vaccine 2011;29:3254-9.

Abbreviation: $\mathrm{Cl}=$ confidence interval.

* Children were classified as below poverty if their total family income was less than the poverty threshold specified for the applicable family size and number of children aged $<18$ years. Children with total family income at or above the poverty threshold specified for the applicable family size and number of children aged $<18$ years were classified as at or above poverty. Poverty thresholds reflect yearly changes in the Consumer Price Index. Additional information is available at http://www.census.gov/hhes/www/poverty.html.

† Statistically significant difference $(p<0.01)$ in estimated vaccination coverage by above and at poverty level and below poverty level.

\section{Seroprevalence of Antibody to Hepatitis A Virus}

Analysis of anti-HAV prevalence from 1999-2000 to 2009-2010, showed an increase of $28.1 \%$ and $15.5 \%$ among children aged 6-11 and $12-19$ years, respectively ( $\mathrm{p} \leq 0.01$ ). Among adults aged 20-29 years and 30-39 years, point estimates of anti-HAV prevalence remained largely unchanged between the two surveys. Prevalence was lower by $21.2 \%$, $16.9 \%$, and $27.4 \%$ among adults aged $40-49,50-59$, and $\geq 60$ years, respectively $(\mathrm{p}<0.01)$. Among all persons aged $\geq 6$ years, the estimated prevalence of anti-HAV decreased from $31.2 \%$ during $1999-2000$ to $26.5 \%$ during 2009-2010, respectively $(\mathrm{p}=0.06)($ Table 4).

During 2009-2010, the prevalence of anti-HAV among U.S.-born residents differed significantly by race/ethnicity.
Overall, prevalence was lowest among non-Hispanic whites, intermediate among non-Hispanic blacks, and greatest among Hispanics, a pattern reflected across all age groups. Among non-Hispanic whites, prevalence was $<20 \%$ in each 10 -year age group of adults aged $20-59$ years (Table 5).

\section{Discussion}

During 1996-2006, ACIP made incremental recommendations for HepA vaccination focused on children and groups with the highest rates of infection (18). National declines occurred in reported cases of HAV disease despite uneven coverage of HepA vaccine. Declines were accompanied by near elimination of absolute disparities by age, race/ ethnicity, and geographic area. In 2011, rates of HAV disease were the lowest ever recorded since HAV disease reporting began in 1966 (15). Moreover, declines were greater than expected on the basis of HepA vaccination coverage. An analysis of the impact of HepA vaccination during 1995-2001 found national coverage among children aged 2-18 years averaged $10 \%$, whereas an estimated $51 \%$ of expected cases of HAV disease in this age group had been prevented in 2001 . Modest vaccination coverage appeared to be associated with a degree of indirect protection for unvaccinated persons in the community, or herd protection (41-43). Possible factors responsible for herd protection from HepA vaccination include the high efficacy of a single dose of vaccine, vaccine-induced immunity of young children who otherwise might sustain communitywide transmission of HAV, and focused vaccination among populations with the highest rates of HAV infection, including disadvantaged populations $(2,41,42)$.

Demonstration projects and other special campaigns to reach children in high-risk areas and disadvantaged populations contributed to initial rapid increases in HepA vaccination (38,44-46). The Vaccines for Children (VFC) program was implemented in 1994 to provide vaccines at no cost to children who might otherwise not be vaccinated because of inability to pay for vaccine (47), and HepA vaccine was added to the VFC program in 1995. During 2008-2010, national $\geq 1$-dose HepA vaccine coverage was greater among children aged 19-35 months living below than, above, or at the poverty level. The availability of VFC program vaccines probably contributed to reductions in economic disparities in access to HepA vaccination and resulted in increased HepA vaccine coverage among economically disadvantaged populations, as has been reported for other recommended childhood vaccines $(47,48)$.

HAV disease is much less common in the United States than in the past primarily because of the success of childhood HepA vaccination. However, nationwide, approximately 1,000 
TABLE 3. Estimated national $\geq 1$-dose and $\geq 2$-dose coverage of hepatitis $A$ vaccine among children aged 19-35 months, by reporting year and race/ethnicity* — National Immunization Survey, United States, 2008-2013

\begin{tabular}{|c|c|c|c|c|c|c|c|c|}
\hline $\begin{array}{l}\text { No. of } \\
\text { doses }\end{array}$ & Year & $\begin{array}{c}\text { White, } \\
\text { non-Hispanic } \\
\%(95 \% \mathrm{Cl})\end{array}$ & $\begin{array}{c}\text { Black, } \\
\text { non-Hispanic } \\
\%(95 \% \mathrm{Cl})\end{array}$ & $\begin{array}{l}\text { Hispanic } \\
\%(95 \% \mathrm{Cl})\end{array}$ & $\begin{array}{c}\text { Al/AN } \\
\%(95 \% \mathrm{Cl})\end{array}$ & $\begin{array}{c}\text { Asian } \\
\%(95 \% \mathrm{Cl})\end{array}$ & $\begin{array}{c}\text { NHOPI } \\
\%(95 \% \mathrm{CI})\end{array}$ & $\begin{array}{l}\text { Multi-racial, } \\
\text { non-Hispanic } \\
\%(95 \% \mathrm{Cl})\end{array}$ \\
\hline \multirow[t]{6}{*}{$\geq 1$} & 2013 & $80.3(78.8-81.8)$ & $82.4(79.1-85.7)$ & $86.0(82.8-89.2)$ & 89.8 (83.1-96.5) & $90.9(85.8-96.0)$ & $91.1(83.3-98.9)$ & $86.7(83.2-90.2)^{\dagger}$ \\
\hline & 2012 & $79.4(78.0-80.8)$ & $83.1(80.2-86.0)$ & $84.2(81.7-86.7)$ & $73.2(52.7-93.7)$ & $87.2(83.3-91.1)$ & $76.8(58.2-95.4)$ & $80.2(75.3-85.1)^{\dagger}$ \\
\hline & 2011 & $77.0(75.7-78.3)$ & $83.1(80.5-85.7)$ & 86.7 (84.8-88.6) & 81.7 (73.5-89.9) & 87.1 (81.5-92.7) & 84.9 (73.2-96.6) & $79.5(74.3-84.7)^{\dagger}$ \\
\hline & 2010 & $72.8(71.2-74.4)$ & 79.8 (76.9-82.7) & $86.3(84.2-88.4)$ & 81.9 (74.4 89.4) & $81.7(76.3-87.1)$ & 77.5 (63.8-91.2) & $81.1(76.5-85.7)^{\dagger}$ \\
\hline & 2009 & $71.3(69.9-72.7)$ & $71.9(68.6-75.2)$ & $81.9(79.5-84.3)$ & $87.0(77.2-96.8)$ & 82.9 (77.1-88.7) & 90.4 (84.2-96.6) & $72.6(67.1-78.1)^{\dagger}$ \\
\hline & 2008 & $64.9(63.4-66.4)$ & $70.5(67.3-73.7)$ & $78.5(76.2-80.8)$ & $74.9(66.6-83.2)$ & 80.7 (75.7-85.7) & 76.7 (61.8-91.6) & $74.1(69.1-79.1)^{\dagger}$ \\
\hline \multirow[t]{6}{*}{$\geq 2$} & 2013 & $53.4(51.5-55.3)$ & $49.1(44.8-53.4)$ & $56.6(52.6-60.6)$ & $58.6(47.1-70.1)$ & $67.3(60.5-74.1)$ & $50.2(26.1-74.3)$ & $57.8(51.8-63.8)^{\dagger}$ \\
\hline & 2012 & $52.6(50.8-54.4)$ & $52.0(48.1-55.9)$ & $54.4(51.0-57.8)$ & $49.8(34.2-65.4)$ & $57.5(49.8-65.2)$ & $48.7(26.9-70.5)$ & $49.4(43.7-55.1)$ \\
\hline & 2011 & $50.0(48.4-51.6)$ & $50.9(47.2-54.6)$ & $56.3(53.1-59.5)$ & $50.3(39.4-61.2)$ & $56.9(49.8-64.0)$ & $53.2(37.0-69.4)$ & $50.2(43.6-56.8)^{\S}$ \\
\hline & 2010 & $45.8(44.2-47.4)$ & $48.6(44.9-52.3)$ & $57.0(53.9-60.1)$ & $50.9(40.9-60.9)$ & $50.8(43.3-58.3)$ & $59.0(42.4-75.6)$ & $49.8(43.2-56.4)^{\dagger}$ \\
\hline & 2009 & $46.2(44.6-47.8)$ & $41.3(37.6-45.0)$ & $49.3(46.0-52.6)$ & $33.2(23.4-43.0)$ & $50.9(41.8-60.0)$ & $61.4(42.9-79.9)$ & $47.8(41.9-53.7)^{\dagger}$ \\
\hline & 2008 & $37.6(36.1-39.1)$ & $39.7(36.0-43.4)$ & $44.7(41.8-47.6)$ & $43.0(33.0-53.0)$ & $47.4(40.0-54.8)$ & 33.5 (14.1-52.9) & $42.3(36.3-48.3)^{\dagger}$ \\
\hline
\end{tabular}

Sources: Include 2009 data for $\geq 1$ dose estimates and 2008 and 2010-2013 data for $\geq 2$ dose estimates. Byrd KK, Santibanez TA, Chaves SS. Predictors of hepatitis A vaccination among young children in the United States. Vaccine 2011;29:3254-9; CDC. National, State, and local area vaccination coverage among children aged 19-35 months-United States, 2008. MMWR 2009;58:921-6; CDC. National, state, and local area vaccination coverage among children aged 19-35 months-United States, 2010. MMWR Morb Mortal Wkly Rep 2011;60:1157-63; CDC. National, state, and local area vaccination coverage among children aged 19-35 months-United States, 2011. MMWR Morb Mortal Wkly Rep 2012;61:689-96; CDC. National, state, and local area vaccination coverage among children aged 19-35 months-United States, 2012. MMWR Morb Mortal Wkly Rep 2013;62:733-40; CDC. National, state, and local area vaccination coverage among children aged 19-35 months-United States, 2013. MMWR Morb Mortal Wkly Rep 2014;63:741-8.

Abbreviations: Al/AN = American Indian/Alaska Native; $\mathrm{Cl}=$ confidence interval; NHOPI = Native Hawaiian and other Pacific Islander.

* Children's race/ethnicity was reported by parent or guardian. Children identified in this report as white, black, Asian, Al/AN, NHOPI, or multiracial were reported by the parent or guardian as non-Hispanic. Children identified as multiracial had more than one race category selected. Children identified as Hispanic might be of any race.

† Statistically significant difference $(p<0.01)$ in estimated vaccination coverage by race/ethnicity.

$\S$ Statistically significant difference $(p<0.05)$ in estimated vaccination coverage by race/ethnicity.

new cases are reported annually, and increases in cases in 2012 among adults aged $\geq 40$ years and increases again in 2013 suggest the epidemiology of HAV infection in the United States might be changing. Although current NNDSS surveillance is missing risk-factor information for $36 \%$ of cases, investigations of acute cases in select sites during 2005-2007 found that travel was the greatest identified risk factor (46\%) (49). Travel-related HAV disease theoretically could be prevented by ACIP-recommended pre-exposure prophylaxis consisting of active or passive immunization or a combination of both active and passive immunization (50). More challenging is the prevention of unknown exposures and prevention of exposures to contaminated food despite continuing efforts by FDA (51). Imports of fresh and frozen fruits and vegetables to the United States from HAV-endemic countries have increased steadily (52). Imported food from HAV-endemic countries has been identified as the source for recent increases in cases of HAV disease in European and other developed countries (53-56). Some investigators suggest that a substantial proportion of cases without recognized exposure are related to contaminated food $(55,56)$. Herd protection provides a barrier against spread of HAV in populations but will not protect susceptible persons when exposed $(43,57)$.

The increase in the prevalence of anti-HAV among U.S.-born children between 1999-2000 and 2009-2010 is indicative of increased protection against HAV infection through greater vaccination coverage, as has been suggested previously (58). However, during 2009-2010, an estimated 50\% or more of non-Hispanic white and non-Hispanic black children aged $<19$ years still lacked anti-HAV protection. These data would not have reflected increases in $\geq 1$-dose childhood HepA vaccination coverage that were present during 2011-2013 NIS data, which would have resulted in increased seroprevalence of anti-HAV among children of all racial/ethnic groups. These data also would not reflect needed improvements in $\geq 2$-dose HepA vaccination among all U.S. children, which is more likely than a single dose of HepA vaccine to ensure protection into adulthood $(59,60)$.

In contrast to increasing anti-HAV prevalence among children, anti-HAV prevalence among U.S.-born adults decreased between the 1999-2000 and 2009-2010 NHANES (Table 4). Even among Hispanic adults, who historically had among the highest seroprevalence of anti-HAV, the 2009-2010 point estimates of prevalence were approximately $50 \%$ among Hispanic adults in the third and fourth decade of life. The lowest prevalence was among U.S.-born non-Hispanic whites ( $<20 \%$ among adults aged $20-59$ years), similar to findings in a more extensive analysis of NHANES data (61). These NHANES estimates suggest that a large proportion of the U.S. adult population is susceptible to acute HAV at ages when the risk for illness and death is greatest. 
Supplement

TABLE 4. National prevalence of total antibody to hepatitis A virus, by age group — National Health and Nutrition Examination Survey, United States, $1999-2000$ and $2009-2010$

\begin{tabular}{|c|c|c|c|c|c|}
\hline \multirow[b]{3}{*}{ Age group (yrs) } & \multicolumn{5}{|c|}{ Anti-HAV prevalence } \\
\hline & \multicolumn{2}{|c|}{ 1999-2000 } & \multicolumn{2}{|c|}{ 2009-2010 } & \multirow[b]{2}{*}{$p$ value } \\
\hline & No. positive/tested & $\%(95 \% \mathrm{Cl})$ & No. positive/tested & $\%(95 \% \mathrm{Cl})$ & \\
\hline $6-11$ & $173 / 805$ & $18.9(10.4-31.8)$ & $547 / 916$ & $47.0(39.2-54.8)$ & $<0.01$ \\
\hline $12-19$ & $402 / 1737$ & $20.0(14.4-27.1)$ & $449 / 1024$ & $35.5(27.7-44.1)$ & $<0.01$ \\
\hline $20-29$ & $116 / 518$ & $17.5(13.5-22.2)$ & $166 / 695$ & $22.2(18.9-25.9)$ & 0.10 \\
\hline $30-39$ & $123 / 509$ & $18.9(14.7-24.0)$ & $92 / 650$ & $13.5(10.2-17.8)$ & 0.09 \\
\hline $40-49$ & $217 / 469$ & $34.8(30.1-39.7)$ & $94 / 632$ & $13.6(10.7-17.1)$ & $<0.01$ \\
\hline $50-59$ & $177 / 381$ & $37.8(31.4-44.7)$ & $159 / 560$ & $20.9(16.8-25.8)$ & $<0.01$ \\
\hline$\geq 60$ & $828 / 1,132$ & $64.3(56.7-71.2)$ & $625 / 1376$ & $36.9(32.6-41.4)$ & $<0.01$ \\
\hline All $(\geq 6)$ & $2,036 / 5,551$ & $31.2(28.1-34.6)$ & $2,132 / 5,853$ & $26.5(23.3-30.0)$ & 0.06 \\
\hline
\end{tabular}

Abbreviations: $\mathrm{Cl}=$ confidence interval; $\mathrm{HAV}=$ hepatitis $\mathrm{A}$ virus.

TABLE 5. National prevalence of total antibody to hepatitis A virus (anti-HAV) by race/ethnicity — National Health and Nutrition Examination Survey, United States, $2009-2010$

\begin{tabular}{|c|c|c|c|c|c|c|}
\hline \multirow{3}{*}{$\begin{array}{l}\text { Age group } \\
\text { (yrs) }\end{array}$} & \multicolumn{6}{|c|}{ Anti-HAV prevalence } \\
\hline & \multicolumn{2}{|c|}{ White, non-Hispanic } & \multicolumn{2}{|c|}{ Black, non-Hispanic } & \multicolumn{2}{|c|}{ Hispanic } \\
\hline & No. positive/tested & $\%(95 \% \mathrm{Cl})$ & No. positive/tested & $\%(95 \% \mathrm{Cl})$ & No. positive/tested & $\%(95 \% \mathrm{Cl})$ \\
\hline $6-11$ & $86 / 284$ & $28.4(22.6-34.9)$ & $98 / 186$ & $50.8(41.7-60.0)$ & $326 / 385$ & $84.0(73.7-90.8)$ \\
\hline $12-19$ & $85 / 371$ & $23.6(16.6-32.4)$ & $92 / 234$ & $38.9(31.0-47.5)$ & $245 / 357$ & $69.4(57.8-79.0)$ \\
\hline $20-29$ & $61 / 368$ & $17.6(14.0-21.9)$ & $31 / 155$ & $20.4(15.2-26.9)$ & $62 / 135$ & $47.0(41.4-52.7)$ \\
\hline $30-39$ & $38 / 417$ & $9.7(6.6-13.9)$ & $24 / 120$ & $20.2(12.9-30.4)$ & 18/87 & $21.4(11.5-36.2)$ \\
\hline 40-49 & $49 / 424$ & $12.0(8.6-16.4)$ & $22 / 124$ & $17.4(9.6-29.4)$ & $21 / 71$ & $31.7(19.9-46.4)$ \\
\hline $50-59$ & $63 / 352$ & $16.6(12.4-22.0)$ & $57 / 133$ & $43.0(35.8-50.5)$ & $38 / 69$ & $57.2(35.9-76.2)$ \\
\hline$\geq 60$ & $343 / 965$ & $32.3(28.7-36.2)$ & $149 / 243$ & $62.8(55.0-70.0)$ & $124 / 153$ & $83.8(74.2-90.2)$ \\
\hline All $(\geq 6)$ & $725 / 3,181$ & $20.3(18.1-22.8)$ & $473 / 1,195$ & $35.0(31.7-38.5)$ & $834 / 1,257$ & $60.1(53.1-66.7)$ \\
\hline
\end{tabular}

Abbreviations: $\mathrm{Cl}=$ confidence interval; $\mathrm{HAV}=$ hepatitis $\mathrm{A}$ virus.

HAV remains endemic in much of the world $(9,12,13,57)$. International travel and the global food economy create conditions that could contribute to HAV infection among an increasingly susceptible U.S. adult population. Targeted or risk-based vaccine recommendations are reported to be more complex to implement than age-based recommendations (62). The current ACIP recommendations for vaccinating adults with identified risk for HAV infection (e.g., travelers, persons with chronic liver disease, and MSM) require providers and patients to have timely knowledge of risk, vaccination history, and possible susceptibility to HAV infection. Lack of provider and patient knowledge has been identified as a barrier to adult vaccination (63). Universal childhood vaccination and risk-based approaches to adult HepA vaccination have been successful in preventing HAV-related hospitalizations (64). However, this success falls short, as demonstrated by very low $(\leq 20 \%)$ adult HepA vaccination coverage among travelers and persons with chronic liver disease, and accompanied by a high proportion of cases of disease among travelers, and hospitalizations among adults with chronic liver disease and other comorbid conditions $(37,39,64,65)$. The increasing proportion of HAV disease cases among adults with identified and unidentified sources of exposure adds importance to considering new strategies for preventing HAV infection among U.S. adults.

\section{Limitations}

The findings presented in this report are subject to at least six limitations. First, ACIP recommends that the first dose of HepA vaccine be administered to children at age 12-23 months and the second dose 6-18 months later. Because NIS surveys children aged 19-35 months, NIS coverage data probably underestimated $\geq 2$-dose HepA completion rates in children receiving a second dose after age 35 months (e.g., at school or child care entry) (66). Second, sample size was insufficient for reliable estimates of vaccine coverage and anti-HAV prevalence among some racial/ethnic groups, as indicated by wide $95 \%$ CIs. Third, race/ethnicity were not categorized similarly in survey data from NIS and NHANES, which prevented certain comparisons. Fourth, NHANES is representative of the noninstitutionalized U.S. civilian population, and results might not be generalizable to the entire U.S. population. Fifth, changes in surveillance methods, definitions, and reporting have occurred 
over the years, which might have resulted in underestimating or overestimating the number of cases diagnosed and nationally reported. Finally, these changes also might account for apparent discrepancies in acute HAV disease rates reported for the same periods $(3,5,6,15)$.

\section{Conclusion}

ACIP-recommended childhood HepA vaccination in the United States has eliminated most absolute disparities in HAV disease by age, racial and ethnic group, and geographic area with relatively modest $\geq 1$-dose and $\geq 2$-dose vaccine coverage. Although population protection (as indicated by vaccination coverage and seroprevalence of anti-HAV) is increasing among children, the proportion of adults with protection has declined. New racial/ethnic-related disparities in protection are becoming evident. It will be years before HepA-vaccinated children replace adults in the population who currently lack protection. Rates of HAV disease have decreased overall; however, since 2007, rates have been higher among adults than among children aged $\leq 9$ years, and rates among older age groups have plateaued or increased since 2011. The gap in HAV disease between young children and adults is an emerging health disparity that will require new strategies to continue progress toward elimination of HAV infection.

\section{Acknowledgments}

Qian Li, James A. Singleton, PhD, Benjamin Kupronis, MPH, Mona Doshani, MD, Melissa Colliers, MD, Ruth Jiles-Chapman, PhD.

\section{References}

1. Murphy TV, Feinstone SM, Bell BP, Hepatitis A. In: Plotkin SA, Orenstein WA, Offit PA, eds. Vaccines. 6th ed. Oxford, United Kingdom: Elsevier Limited; 2012.

2. Armstrong GL, Bell BP. Hepatitis A virus infections in the United States: model-based estimates and implications for childhood immunization. Pediatrics 2002;109:839-45. http://dx.doi.org/10.1542/peds.109.5.839.

3. CDC. Prevention of hepatitis A through active or passive immunization: recommendations of the Advisory Committee on Immunization Practices (ACIP). MMWR Recomm Rep 1996;45(No. RR-15).

4. Bell BP. Hepatitis A and hepatitis $B$ vaccination of patients with chronic liver disease. Acta Gastroenterol Belg 2000;63:359-63.

5. CDC. Viral hepatitis surveillance-United States, 2007. MMWR Surveill Summ 2009;58(No. SS-3).

6. CDC. Prevention of hepatitis A through active or passive immunization: recommendations of the Advisory Committee on Immunization Practices (ACIP). MMWR Recomm Rep 1999;48(No. RR-12).

7. Hadler SC, McFarland L. Hepatitis in day care centers: epidemiology and prevention. Rev Infect Dis 1986;8:548-57. http://dx.doi. org/10.1093/clinids/8.4.548.

8. Wasley A, Fiore A, Bell BP. Hepatitis A in the era of vaccination. Epidemiol Rev 2006;28:101-11. http://dx.doi.org/10.1093/epirev/ $\operatorname{mxj012.}$
9. Tanaka J. Hepatitis A shifting epidemiology in Latin America. Vaccine 2000;18(Suppl 1):S57-60. http://dx.doi.org/10.1016/S0264-410X (99)00466-1.

10. Chen Y, Zhang X-J, Zhao Y-L, et al. Waning of anti-HAV immunity in Shijiazhuang prefecture, Hebei province, China: a comparison of seroprevalence between 1992 and 2011. Vaccine 2014;32:6227-32. http://dx.doi.org/10.1016/j.vaccine.2014.09.022.

11. Lemon SM, Shapiro CN. The value of immunization against hepatitis A. Infect Agents Dis 1994;3:38-49.

12. Jacobsen KH. Hepatitis A virus in West Africa: Is an epidemiological transition beginning? Niger Med J 2014;55:279-84. http://dx.doi. org/10.4103/0300-1652.137185.

13. Jacobsen KH, Wiersma ST. Hepatitis A virus seroprevalence by age and world region, 1990 and 2005. Vaccine 2010;28:6653-7. http://dx.doi. org/10.1016/j.vaccine.2010.08.037.

14. Bell BP, Shapiro CN, Alter MJ, et al. The diverse patterns of hepatitis A epidemiology in the United States-implications for vaccination strategies. J Infect Dis 1998;178:1579-84. http://dx.doi.org/10.1086/314518.

15. CDC. Viral hepatitis surveillance: United States, 2011. Atlanta, GA: US Department of Health and Human Services, CDC; 2013. http:// www.cdc.gov/hepatitis/Statistics/2011Surveillance.

16. Wasley A, Samandari T, Bell BP. Incidence of hepatitis A in the United States in the era of vaccination. JAMA 2005;294:194-201. http://dx.doi. org/10.1001/jama.294.2.194.

17. McQuillan GM, Kruszon-Moran D, Kottiri BJ, Curtin LR, Lucas JW, Kington RS. Racial and ethnic differences in the seroprevalence of 6 infectious diseases in the United States: data from NHANES III, 1988-1994. Am J Public Health 2004;94:1952-8. http://dx.doi. org/10.2105/AJPH.94.11.1952.

18. CDC. Prevention of hepatitis A through active or passive immunization: recommendations of the Advisory Committee on Immunization Practices (ACIP). MMWR Recomm Rep 2006;55(No. RR-7):1-23.

19. Penman-Aguilar A, Bouye K, Liburd L. Background and rationale. In: Strategies to reduce health disparities: selected CDC-sponsored interventionsUnited States, 2016. MMWR Suppl 2016;65(No. Suppl 1).

20. Food and Drug Administration. Silver Spring, MD: US Department of Health and Human Services, Food and Drug Administration; 2015. http://www.fda.gov/BiologicsBloodVaccines/Vaccines/ ApprovedProducts/default.htm.

21. Werzberger A, Mensch B, Kuter B, et al. A controlled trial of a formalininactivated hepatitis A vaccine in healthy children. $\mathrm{N}$ Engl J Med 1992;327:453-7. http://dx.doi.org/10.1056/NEJM199208133270702.

22. Innis BL, Snitbhan R, Kunasol P, et al. Protection against hepatitis A by an inactivated vaccine. JAMA 1994;271:1328-34. http://dx.doi. org/10.1001/jama.1994.03510410040030.

23. CDC. National Immunization Survey. Atlanta, GA: US Department of Health and Human Services, CDC; 2015. http://www.cdc.gov/nchs/nis.htm.

24. CDC. Hepatitis A vaccination coverage among children aged 24-35 months-United States, 2003. MMWR Morb Mortal Wkly Rep 2005;54:141-4.

25. CDC. National, state, and local area vaccination coverage among children aged 19-35 months-United States, 2008. MMWR Morb Mortal Wkly Rep 2009;58:921-6.

26. CDC. National, state, and local area vaccination coverage among children aged 19-35 months_-United States, 2010. MMWR Morb Mortal Wkly Rep 2011;60:1157-63.

27. Byrd KK, Santibanez TA, Chaves SS. Predictors of hepatitis A vaccination among young children in the United States. Vaccine 2011;29:3254-9. http://dx.doi.org/10.1016/j.vaccine.2011.02.028.

28. CDC. National, state, and local area vaccination coverage among children aged 19-35 months-United States, 2011. MMWR Morb Mortal Wkly Rep 2012;61:689-96. 
29. CDC. National, state, and local area vaccination coverage among children aged 19-35 months_-United States, 2012. MMWR Morb Mortal Wkly Rep 2013;62:733-40.

30. CDC. National, state, and local area vaccination coverage among children aged 19-35 months_-United States, 2013. MMWR Morb Mortal Wkly Rep 2014;63:741-8.

31. Dorell CG, Yankey D, Byrd KK, Murphy TV. Hepatitis A vaccination coverage among adolescents in the United States. Pediatrics 2012;129:21321. http://dx.doi.org/10.1542/peds.2011-2197.

32. CDC. National Health Interview Survey. Atlanta, GA: US Department of Health and Human Services, CDC; 2015. http://www.cdc.gov/nchs/nhis.htm.

33. CDC. National Notifiable Diseases Surveillance System. Atlanta, GA: US Department of Health and Human Services, CDC; 2015. http:// www.cdc.gov/nndss.

34. CDC. Viral Hepatitis Surveillance, United States 2013. Atlanta, GA: US Department of Health and Human Services, CDC. http://www.cdc.gov/ hepatitis/statistics/2013surveillance/pdfs/2013hepsurveillancerpt.pdf.

35. CDC. National Health and Nutrition Examination Survey. Atlanta, GA: US Department of Health and Human Services, CDC; 2015. http:// www.cdc.gov/nchs/nhanes/nhanes_questionnaires.htm.

36. Lu P-J, Euler GL, Hennessey KA, Weinbaum CM. Hepatitis A vaccination coverage among adults aged 18-49 years in the United States. Vaccine 2009;27:1301-5. http://dx.doi.org/10.1016/j.vaccine.2008.12.054.

37. Williams WW, Lu P-J, O'Halloran A, et al. Noninfluenza vaccination coverage among adults-United States, 2012. MMWR Morb Mortal Wkly Rep 2014;63:95-102.

38. Singleton RJ, Hess S, Bulkow LR, Castrodale L, Provo G, McMahon BJ. Impact of a statewide childhood vaccine program in controlling hepatitis A virus infections in Alaska. Vaccine 2010;28:6298-304. http:// dx.doi.org/10.1016/j.vaccine.2010.06.113.

39. CDC. Viral hepatitis surveillance: United States, 2012. Atlanta, GA: US Department of Health and Human Services, CDC; 2014. http:// www.cdc.gov/hepatitis/Statistics/2012Surveillance/index.htm.

40. Collier MG, Khudyakov YE, Selvage D, et al. Outbreak of hepatitis A in the USA associated with frozen pomegranate arils imported from Turkey: an epidemiological case study. Lancet Infect Dis 2014;14:97681. http://dx.doi.org/10.1016/S1473-3099(14)70883-7.

41. Samandari T, Bell BP, Armstrong GL. Quantifying the impact of hepatitis A immunization in the United States, 1995-2001. Vaccine 2004;22:4342-50. http://dx.doi.org/10.1016/j.vaccine.2004.04.014.

42. Armstrong GL, Billah K, Rein DB, Hicks KA, Wirth KE, Bell BP. The economics of routine childhood hepatitis A immunization in the United States: the impact of herd immunity. Pediatrics 2007;119:e22-9. http:// dx.doi.org/10.1542/peds.2006-1572.

43. John TJ, Samuel R. Herd immunity and herd effect: new insights and definitions. Eur J Epidemiol 2000;16:601-6. http://dx.doi. org/10.1023/A:1007626510002.

44. Amon JJ, Darling N, Fiore AE, Bell BP, Barker LE. Factors associated with hepatitis A vaccination among children 24 to 35 months of age: United States, 2003. Pediatrics 2006;117:30-3. http://dx.doi. org/10.1542/peds.2005-0286.

45. McMahon BJ, Beller M, Williams J, Schloss M, Tanttila H, Bulkow L. A program to control an outbreak of hepatitis A in Alaska by using an inactivated hepatitis A vaccine. Arch Pediatr Adolesc Med 1996;150:733-9. http://dx.doi.org/10.1001/archpedi.1996.02170320079014.

46. Averhoff F, Shapiro CN, Bell BP, et al. Control of hepatitis A through routine vaccination of children. JAMA 2001;286:2968-73. http:// dx.doi.org/10.1001/jama.286.23.2968.

47. Walker AT, Smith PJ, Kolasa M. Reduction of racial/ethnic disparities in vaccination coverage, 1995-2011. MMWR Suppl 2014;63(Suppl 1):7-12.
48. Whitney CG, Zhou F, Singleton J, Schuchat A. Benefits from immunization during the vaccines for children program era-United States, 1994-2013. MMWR Morb Mortal Wkly Rep 2014;63:352-5.

49. Klevens RM, Miller JT, Iqbal K, et al. The evolving epidemiology of hepatitis A in the United States: incidence and molecular epidemiology from population-based surveillance, 2005-2007. Arch Intern Med 2010;170:1811-8. http://dx.doi.org/10.1001/archinternmed.2010.401.

50. CDC. Update: prevention of hepatitis A after exposure to hepatitis A virus and in international travelers: updated recommendations of the Advisory Committee on Immunization Practices (ACIP). MMWR Morb Mortal Wkly Rep 2007;56:1080-4.

51. Hampton T. Tweaking proposed food safety rules. JAMA 2014;312:1625. http://dx.doi.org/10.1001/jama.2014.13253.

52. US Department of Agriculture. Economic Research Service. U.S. food imports. Washington, DC: US Department of Agriculture, Economic Research Service; 2015. http://www.ers.usda.gov/data-products/us-foodimports.aspx.

53. European Food Safety Authority, 2014. Tracing of food items in connection to the multinational hepatitis A virus outbreak in Europe. EFSA Journal 2014;12:3821-4007.

54. O'Dowd A. Source of hepatitis A outbreak in Europe may be frozen berries. BMJ 2014;348:g2852. http://dx.doi.org/10.1136/bmj.g2852.

55. Petrignani M, Verhoef L, Vennema H, et al. Underdiagnosis of foodborne hepatitis A, The Netherlands, 2008-2010. Emerg Infect Dis 2014;20:596-602. http://dx.doi.org/10.3201/eid2004.130753.

56. Donnan EJ, Fielding JE, Gregory JE, et al. A multistate outbreak of hepatitis A associated with semidried tomatoes in Australia, 2009. Clin Infect Dis 2012;54:775-81. http://dx.doi.org/10.1093/cid/cir949.

57. Mohd Hanafiah K, Jacobsen KH, Wiersma ST. Challenges to mapping the health risk of hepatitis A virus infection. Int J Health Geogr 2011;10:57. http://dx.doi.org/10.1186/1476-072X-10-57.

58. Klevens RM, Kruszon-Moran D, Wasley A, et al. Seroprevalence of hepatitis A virus antibodies in the U.S.: results from the National Health and Nutrition Examination Survey. Public Health Rep 2011;126:522-32.

59. Raczniak GA, Bulkow LR, Bruce MG, et al. Long-term immunogenicity of hepatitis A virus vaccine in Alaska 17 years after initial childhood series. J Infect Dis 2013;207:493-6. http://dx.doi.org/10.1093/infdis/jis710.

60. Byrd KK, Bruden DL, Bruce MG, et al. Long-term immunogenicity of inactivated hepatitis A vaccine: follow-up at 15 years. J Pediatr Infect Dis 2010;5:321-7.

61. Klevens RM, Denniston MM, Jiles-Chapman RB, Murphy TV. Decreasing immunity to hepatitis A virus infection among US adults: findings from the National Health and Nutrition Examination Survey (NHANES), 1999-2012. Vaccine 2015;33:6192-8. http://dx.doi. org/10.1016/j.vaccine.2015.10.009.

62. Task Force on Community Preventive Services. Vaccine-preventable diseases. In: Zaza S, Briss PA, Harris KW, eds. The guide to community preventive services: what works to promote health? New York, NY: Oxford University Press; 2005.

63. National Vaccine Advisory Committee. Recommendations from the National Vaccine Advisory Committee: standards for adult immunization practice. Public Health Rep 2014;129:115-23.

64. Collier MG, Tong X, Xu F. Hepatitis A hospitalizations in the United States, 2002-2011. Hepatology 2015;61:481-5. http://dx.doi. org/10.1002/hep. 27537.

65. CDC. Noninfluenza vaccination coverage among adults-United States, 2011. MMWR Morb Mortal Wkly Rep 2013;62:66-72.

66. Immunization Action Coalition. Hepatitis A prevention mandates for daycare and K-12. Saint Paul, MN: Immunization Action Coalition; 2015. http://www.immunize.org/laws/hepa.asp. 